\title{
La calidad de la democracia en el Perú
}

\author{
CARLos Ugo SANTANDER \\ Doctor en Sociología (UnB) \\ Profesor de la Universidade Federal de Goiás \\ Goiânia, Goiás, Brasil \\ csantander@hotmail.com
}

CHARLES KENNEY

Doctor en Ciencia Política (University of Notre Dame, Estados Unidos) Profesor de la University of Oklahoma

Norman, Estados Unidos

ckenney@ou.edu

Resumen Este trabajo analiza la experiencia democrática peruana a partir del referencial teórico-metodológico presentado por Leonardo Morlino sobre calidad de la democracia. De forma resumida se trata de pasar de los estudios de transitología - propios de las décadas de 1980 y 1990, cuando países como Perú y sus vecinos logran sus respectivas transiciones y consolidaciones democráticas - en dirección a investigaciones preocupadas con la calidad de la democracia. A pesar de la regresión autoritaria en los 1990 y la vuelta al régimen democrático en 2001, la democracia peruana aún presenta una serie de desafíos que pueden llevar a otra regresión autoritaria o a la propia devaluación de la democracia. Existen claras evidencias con resultados significativos en dimensiones relacionadas a los derechos políticos y al control de gobernantes e instituciones, pero los problemas se concentran en dimensiones relacionadas a la responsabilidad y legitimidad, al imperio de la ley y a la igualdad y solidaridad.

Palabras clave: Perú; calidad de la democracia; responsabilidad y legitimidad; autoritarismo; solidaridad e igualdad.

6 6NO, NO HAY PAÍS MÁS DIVERSO", reza el conocido discurso de José María Arguedas (1969). Y lo cierto es que pretender captar la diversidad de experiencias de democracia a lo largo y ancho del Perú en los últimos 14 años excede los límites del presente artículo. ¿Cómo vive la democracia el migrante ancashino que reside ahora en San Juan de Lurigancho en Lima, las señoras quechua hablantes de Patacancha a los 4.000 metros sobre el nivel del mar en el Cusco, o la comunidad indígena Ese'Eja del pueblo llamado Infierno en el río Tambopata, todos estos partícipes, ahora activos, ahora pasivos, del régimen democrático que en 2015 cumple 14 años? Parecen pocos, 14 años, desde que huyó Alberto Fujimori a Japón y se reinició la democracia, hasta que uno se da cuenta que ningún régimen en el Perú, autoritario o democrático, ha durado más de 12 años desde que expulsaron al presidente Guillermo Billinghurst (1912-1914) del poder en 1914. En cuanto pensamos que este régimen va a seguir en pie, comenzamos a pasar de preocuparnos principalmente por la sobrevivencia de la democracia a pensar en las cualidades del régimen democrático que sobrevive. En este artículo pretendemos analizar, a partir de ocho dimensiones, la calidad democrática del régimen peruano nacido en 2001. 
Con la caída del gobierno de Fujimori (19902000) y Vladimiro Montesinos, el éxito de la transición con Valentín Paniagua (2000-2001), las elecciones y el inicio del gobierno de Alejandro Toledo (2001-2006), el Perú pasó desde un régimen autoritario competitivo a la democracia actual. Entonces, ¿a qué tipo de régimen democrático hemos llegado? ¿Cuáles son sus cualidades más sobresalientes y cuáles son sus defectos?

El Perú de hoy no es el Perú de hace una década, y se perciben cambios importantes en la forma en que los ciudadanos viven la democracia, aunque los problemas profundos del país se resisten a solucionarse. En el 2000 la preferencia por la democracia entre los peruanos llegó al 64\%, disminuyendo significativamente al 40\% en el 2005, para oscilar positivamente en el 2010, llegando al 61\%, según Latinobarómetro ${ }^{1}$. Del mismo modo, la satisfacción con el funcionamiento de la democracia en el Perú subió del 7\% en el 2004 al 31\% en el 2011, pero aunque la cifra es positiva, comparativamente sigue estando por debajo del promedio de América Latina, que es del 39\%. Si bien el Perú ha gozado de la década de crecimiento económico más fuerte desde 1950, el descontento social es muy alto. Algunas de las razones se perciben con facilidad, pero hay otras que son menos visibles, y descubrir las fuerzas de la democracia peruana para superar estos desafios es también una tarea importante.

\section{Introducción a las ocho dimensiones de la calidad democrática en el Perú}

Este estudio se fundamenta en las ocho dimensiones propuestas por Leonardo Morlino, que se refiere a una democracia de calidad como "una estructura institucional estable que permite que los ciudadanos alcancen la libertad e igualdad mediante el legítimo y correcto funcionamiento de sus instituciones y mecanismos" (Morlino, 2011). Esto es, calidad en términos de resultados, calidad en términos de contenido y calidad en términos de procedimientos.

Se distinguen ocho dimensiones de la democracia, las que se miden en una escala de puntuación de 2,0 a 5,0, y cada una de estas tiene sus sub-dimensiones. En vez de agregar las varias dimensiones para obtener en un solo número el nivel o la calidad de la democracia, intentamos distinguir estas dimensiones y medir cada una de ellas. Lo interesante, por lo tanto, no es solamente el valor agregado de cada dimensión, sino también el valor asignado a cada sub-dimensión. A continuación, exploraremos la democracia imperfecta pero valiosa que nace con las elecciones de 2001, enfocando con especial atención los años más recientes.

Las primeras cinco dimensiones son las orientadas principalmente a los procesos y procedimientos de la democracia: el imperio de la ley (rule of law o estado de derecho), la rendición de cuentas electoral (accountability electoral o mayoría vertical), la rendición de cuentas inter-institucional (accountability inter-institucional o mayoría horizontal), la participación política y la competencia política. Las dimensiones de igualdad y libertad corresponden a valores que se asocian con la democracia desde la antigüedad y constituyen calidades correspondientes al contenido principal de la democracia, mientras que el resultado esperado de la democracia es que sea responsable, es decir, que responda a las voluntades, necesidades y aspiraciones del público.

\section{La rendición de cuentas electoral}

La rendición de cuentas o accountability electoral es una dimensión fundamental para la existencia de una democracia representativa, ya que es por medio de los representantes que el público gobierna y ejerce su poder, es decir, hace democracia. Si los llamados a ser representantes no cumplen al representar los intereses y las opiniones de sus representados, el público ya no gobierna, por lo tanto, no hay democracia. La rendición de cuentas por medios electorales es una de las formas por la cual los ciudadanos ejercen un control sobre sus representantes, y para que este control sea eficaz es necesario que los procesos electorales sean libres y justos, que haya libertad y transparencia en la organización y financiación de los partidos políticos, y que existan alternativas partidarias con cierta estabilidad de presencia electoral.

La rendición de cuentas electoral en el Perú recibe una pontuación de 3,9 en el promedio de las tres sub-dimensiones. El país se desempeña mejor en la realización de elecciones libres, justas y competitivas. Desde 2001 las elecciones se han realizado de manera libre y justa, bajo autoridades electorales razonablemente imparciales y competentes y con procedimientos suficientemente objetivos para que el sufragio sea secreto y eficaz. Todo eso a pesar que en un informe de Latinobarómetro solo el 30\% del público peruano consideraba en el 2009 que las elecciones eran limpias y el 70\% las consideraba fraudulentas, ubicando al Perú en el tercer lugar entre los países con menos confianza en el ejercicio electoral ${ }^{2}$. Solo Honduras y México tuvieron niveles inferiores en el 2009. Según el Latin American Public Opinion Project (LAPOP), el índice de confianza en las elecciones en el Perú fue del 44\% en 
Fig. 01 - Dimensiones de la calidad de la democracia en el Perú, 2012

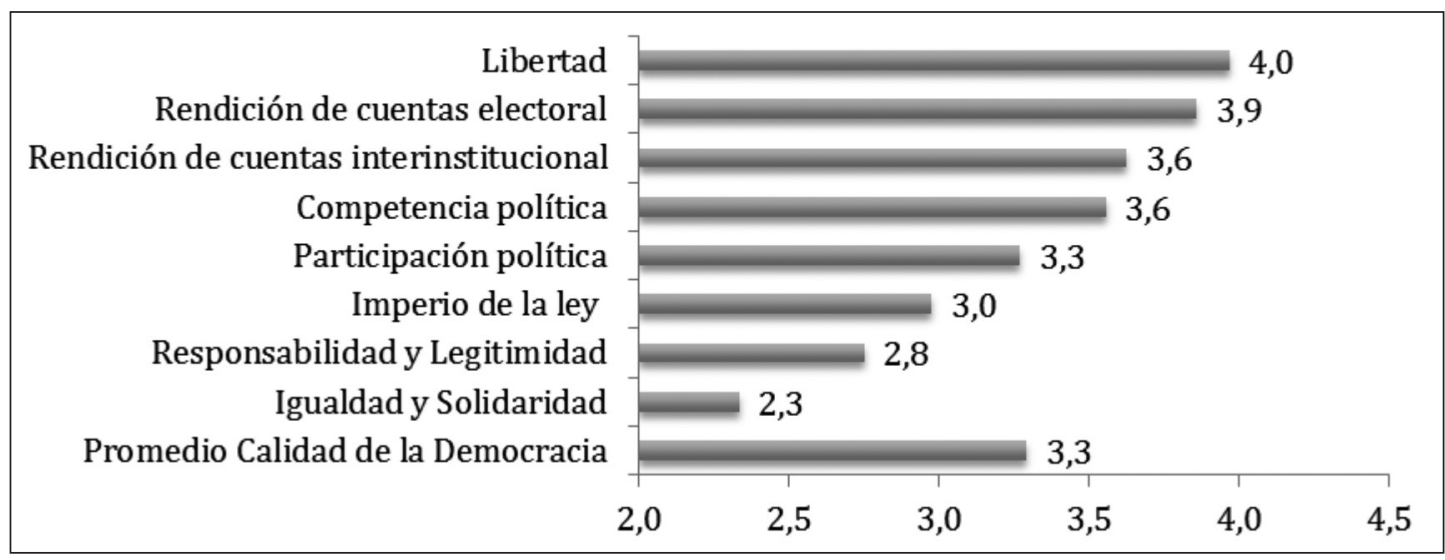

Fuente: Elaboración propia

Fig. 02 - La rendición de cuentas electoral en el Perú, 2012

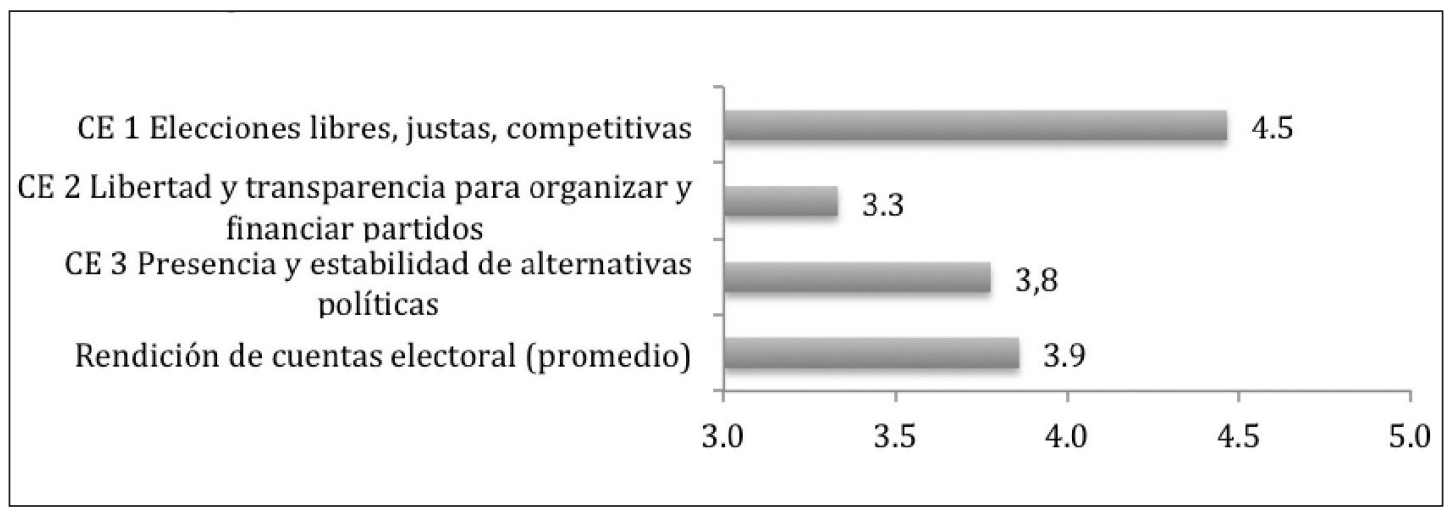

Fuente: Elaboración propia

2008, con solo Honduras, Haití, y Paraguay por debajo, pero en 2012 el índice de confianza en las elecciones había subido al 66\%, ubicándose entre los cinco paises con más confianza en las elecciones ${ }^{3}$.

Sin embargo, el problema más importante en esta dimensión es la falta de continuidad en el tiempo de las alternativas políticas. La libertad para organizar partidos en el Perú es alta, y por ello hay presencia de muchas organizaciones políticas. Un ejemplo de ello es que en 2006 compitieron 20 partidos a las elecciones, mientras que en 2011 el número disminuyó a 13 partidos. La volatilidad electoral en las elecciones presidenciales ha sido bastante significativa, ubicando al Perú como uno de los países con menor estabilidad en la oferta de alternativas políticas. Así desde los años 1990 el Perú ha tenido uno de los sistemas partidarios menos institucionalizados de América Latina (Mainwaring y Scully, 1995; Payne, 2002; Mainwaring, Bejarano y Pizarro, 2008; Jones, 2010; Alcántara Sáez, 2012), hasta el punto que algunos lo llaman de un "no-sistema" (Sánchez, 2009).

Otro indicador de la inestabilidad de alternativas políticas es la suerte que han corrido los partidos de los presidentes después de su periodo de gobierno. En las elecciones de 2001, 2006 y 2011, el partido que ganó la presidencia en la elección anterior fue incapaz de presentar un candidato a la presidencia para el periódo siguiente (Santander, 2008), situación que se da también en la elección a cargos legislativos. Es verdad que la inestabilidad de la oferta electoral no es total, pero en todo caso muestra la naturaleza de las plataformas políticas, como en los casos de lo que queda del APRA reunido alrededor de la figura del dos veces presidente Alan García, de los seguidores del encarcelado ex-presidente Alberto Fujimori y de los que se agrupan alrededor del ex-presidente Alejandro Toledo, que no han mostrado la capacidad de recuperar un lugar en el sistema político después de casi desaparecer, pero a pesar de ello se mantienen presentes como agrupaciones electoralmente dependientes de sus respectivos líderes históricos.

Un problema significativo con respecto a la rendición de cuentas electoral es la falta de transparencia en la financiación de las campañas electorales, así como en la contabilidad interna de los partidos. En un estudio comparado de ocho países latinoamericanos Transparencia 
Fig. 03 - La rendición de cuentas institucional en el Perú, 2012

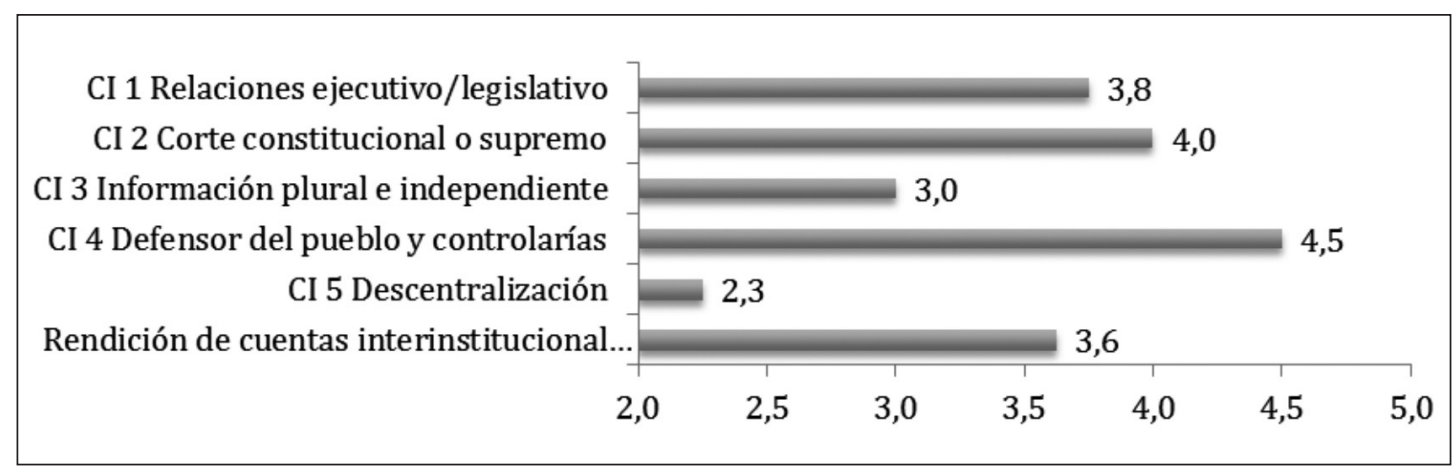

Fuente: Elaboración propia

Internacional ha puesto de relieve que las leyes peruanas que regulan la contabilidad interna de los partidos eran satisfactorias, así como el alcance y la profundidad de los datos requeridos, sin embargo deja mucho que desear la publicidad de estos datos, así como la fuerza de los órganos de control que puedan sancionar a los partidos que no cumplen oportunamente con la rendición ${ }^{4}$. Los países mejor evaluados, Argentina y Colombia, recibieron 21 puntos, el $50 \%$ de los 42 posibles. El Perú, por su parte, recibió 17 puntos (40\%), ligeramente por encima del promedio de 15 (36\%).

En fin, hay participación eficaz de votantes, y la composición del Legislativo y el Ejecutivo reflejan en un alto grado las opciones de los votantes, pero la rendición de cuentas electoral en el Perú está limitada al poco control al flujo de recursos que se destinan a financiar los partidos y las campañas electorales en los diversos niveles.

\section{La rendición de cuentas interinstitucional}

Si el primer requerimiento de un gobierno es gobernar, y si para que el gobierno sea democrático es necesario que sea controlado por el público, también es necesario que el gobierno se controle a sí mismo, que haya mecanismos por medio de los cuales los que ejercen el poder se vigilen entre sí y que sean capaces - y que ejerzan la voluntad - de controlarse mutuamente. En un sistema presidencial esto puede realizarse de varias maneras, entre ellas, el control que se ejerce entre el Ejecutivo y el Legislativo, entre éstos y el tribunal constitucional, por medio de contralorías y del defensor del pueblo y por la descentralización del poder acompañado por mecanismos de control entre el poder central y los poderes descentralizados. Hay varias con- diciones adicionales necesarias, siendo la principal que haya fuentes de información plurales e independientes.

El Perú tiene un nivel relativamente alto de rendición de cuentas inter-institucional, con una puntuación global de 3,6 (de 5,0). Entre las dimensiones de calidad democrática en el Perú, esta es una de las más altas.

Un elemento importante para la rendición de cuentas interinstitucional es la relación entre el Ejecutivo y el Legislativo. En el pasado, uno de los obstáculos principales para la rendición de cuentas fue el control unipartidario del Congreso por una mayoría partidaria sometida al presidente, pero desde 2001 ningún presidente ha llegado al poder con un partido con mayoría absoluta en el Congreso unicameral. El partido de Alejandro Toledo tuvo el 38\% de los escaños al iniciar su presidencia en 2001, el APRA de Alan García tuvo el 30\% en 2006, y Ollanta Humala fue elegido en 2011 a la cabeza de una alianza que alcanzó el 36\% de los escaños. La necesidad de construir y mantener una coalición permite un mayor grado de control parlamentario del Ejecutivo, aunque no tan grande como cuando hay una oposición unificada con mayoría parlamentaria.

Lo que más éxito ha tenido en el Perú ha sido el control que en determinados momentos han ejercido la Defensoría del Pueblo, el Tribunal Constitucional y los organismos especializados de control. Se requiere el voto de dos tercios de los miembros del Congreso para nombrar y para remover al Defensor del Pueblo, permitiéndole cierta autonomía respecto a los otros poderes. Gracias a su autonomía y a la eficacia de su gestión, durante muchos años ha sido una de las instituciones del Estado que ha despertado mayor confianza en el público. En 2008, por ejemplo, cuando un porcentaje de solo el 20\% de los peruanos decían que tenían confianza en Ejecutivo, Congreso, Poder Judicial, Tribunal Constitucional y Fiscalía, el 56\% expresaba confianza en la Defensoría del Pueblo (Apoyo y Mercado, septiembre de 2008). En noviembre de 2010, la gestión de 
la Defensora del Pueblo, Beatríz Merino, fue aprobada por el 52\% de los encuestados, 20 puntos por encima del gobierno en su conjunto y de los otros poderes del Estado (Apoyo y Mercado, noviembre de 2010). En 2012, la confianza de los otros poderes del Estado había crecido, reduciéndose así la brecha entre estos y la Defensoría del Pueblo, según datos de LAPOP, pero la defensoría seguía gozando de bastante prestigio en su tarea de abogar por los ciudadanos ante los poderes del Estado y de esa manera ejercer un control sobre las acciones de éstos.

Otro órgano importante para la rendición de cuentas interinstitucional es el Tribunal Constitucional, formado por siete miembros nombrados por dos tercios del Congreso y con un mandato fijo de cinco años. Aunque el desempeño del Tribunal Constitucional no ha sido tan bueno como el de la Defensoría del Pueblo, se ha asentado como institución autónoma de los otros poderes y ha sabido en algunos momentos ejercer un control significativo sobre las acciones de estos, aunque todavía queda mucho por hacer.

Otras instituciones de control tienen menos autonomía. El Contralor General de la República es nombrado por el presidente y una mayoría del Congreso y por ello es menos autónomo de los partidos gobernantes que el Defensor del Pueblo y el Tribunal Constitucional. El Contralor General es nombrado para un mandato de 7 años, aunque pueda ser removido por el Congreso. Esto significa que el contralor va a permanecer en su cargo aunque el partido de gobierno termine su periodo. Así, el contralor nombrado en el primer año del gobierno de Toledo permaneció en el puesto hasta dos años después que este presidente hubiera dejado el poder. García (2006-2011) tardó siete meses en nombrar un nuevo contralor, que seguirá en el puesto hasta después de las elecciones generales de abril de 2016, que definirán el sucesor de Humala. Dado que el momento de mayor fiscalización de un gobierno suele ser cuando éste deja el poder y un gobierno alternativo inicia su periodo, en el Perú la fiscalización puede ser menor al haber sido el contralor nombrado por el partido saliente.

La Controlaría General de la República es vista con menos confianza por parte de los ciudadanos. En 2008, cuando el índice de confianza del Defensor del
Pueblo era del 51,7\%, el que le correspondía a la controlaría era del 40,9\%, que lo ubicaba entre el Tribunal Constitucional $(43,4 \%)$ y la Policía Nacional $(38,8 \%)$. Cuando en 2011 se preguntó en que instituciones confiaba el público para luchar con efectividad contra la corrupción, la Defensoría del Pueblo recibió el apoyo del $42 \%$ de los encuestados, mientras la controlaría recibió solamente el 16\%, poco más que el desacreditado Poder Judicial (14\%) (Apoyo y Mercado, octubre de 2011).

En resumen, la falta de un partido mayoritario en el gobierno y la existencia de instituciones de control y rendición de cuentas que funcionan con autonomía respecto al gobierno crean condiciones para una rendición de cuentas interinstitucional que supera al que se encuentra en la mayoría de los países latinoamericanos, sin que esto no signifique que aún quede mucho por lograr en este campo.

\section{La competencia política}

La competencia política en el Perú recibe una puntación de 3,6, en el promedio de las tres sub-dimensiones. Las elecciones son justas y libres, un punto que se ha desarrollado con detalle en el apartado sobre la rendición de cuentas electoral. En Perú no hay partidos fuertes que dominen la política o que restrinjan la opción electoral efectiva - no hay partidocracia -, y con frecuencia surgen nuevos partidos y organizaciones políticas El sistema también es bastante abierto, con un número alto de partidos que compiten en elecciones nacionales y con una distribución de votos muy amplia entre los partidos. En 2001, 2006 y 2011, compitieron a cada elección un promedio de 17 partidos en la disputa para el congreso unicameral y 13 partidos en las elecciones presidenciales.

La implementación de una barrera electoral (4\% en 2006 y 5\% en 2011) redujo el número de partidos representados en el congreso (de 11 en 2001 a 7 en 2006, para luego llegar a 6 en 2011), pero es dificil ver en esto una reducción significativa de la competencia. En todo caso el número efectivo de partidos en las elecciones legislativas de 2011 fue de 4. La competitividad también se nota en los márgenes que separan a los candidatos presidenciales con éxito de los otros, ya que el promedio

Fig. 04 - La competencia política en el Perú, 2012

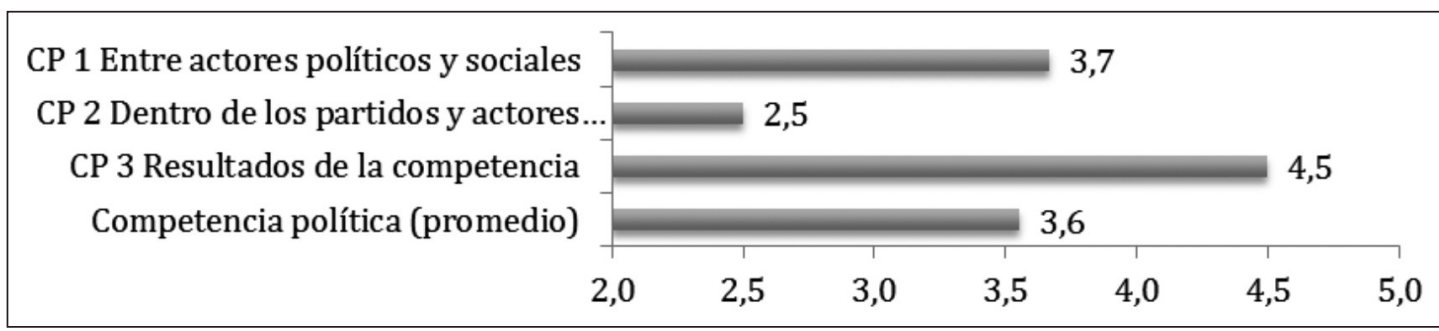

Fuente: Elaboración propia 
Gráfico 01 - Número efectivo de partidos

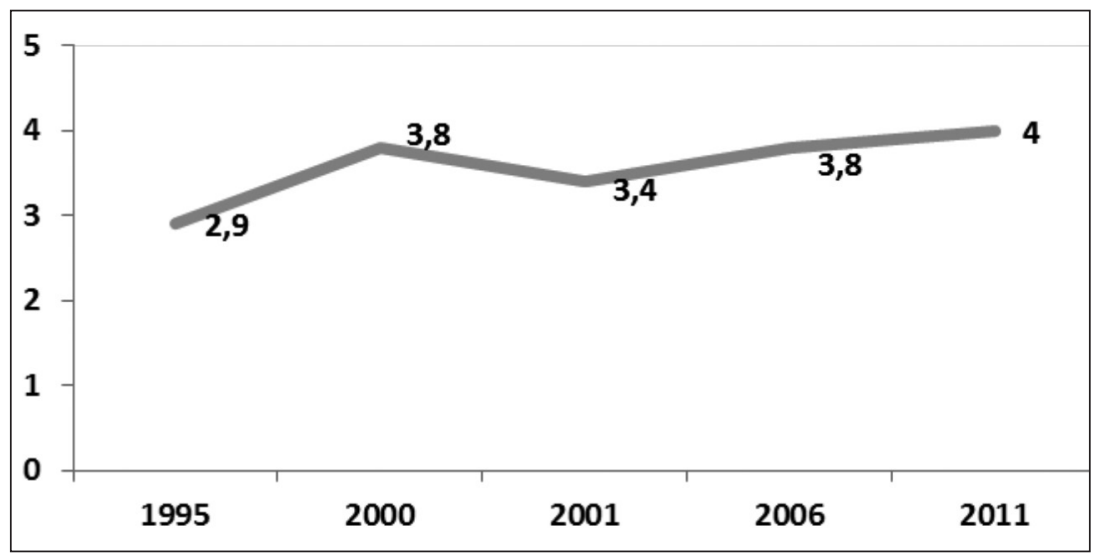

Fuente: Elaboración propia

de la diferencia entre el segundo y el tercer candidato para pasar a la segunda vuelta en 2001, 2006 y 2011 fue del 3,3\% y el promedio del margen de victoria en la segunda vuelta fue de $4,8 \%$. Ningún presidente ha sido elegido desde 2001 con una mayoría amplia en el congreso unicameral. Los partidos o las alianzas electorales de los presidentes elegidos han logrado un promedio del $35 \%$ de los escaños en el congreso, y todos se han visto forzados a crear coaliciones pos-electorales para alcanzar una mayoría en el congreso.

La competencia al interior de las organizaciones políticas y sociales es más débil. Muchas organizaciones políticas son proyectos personalistas o partidos dominados por un líder, de tal modo que la competencia real en su interior es limitada, aun cuando hay mecanismos de competencia formales como elecciones internas y asambleas para designar candidatos y líderes. Hay mucha variación en este sentido, ya que algunos partidos y organizaciones han institucionalizado la competencia interna de forma más democrática, mientras que otras organizaciones políticas y sociales operan como instituciones informales poco competitivas.

\section{La participación política}

La participación política en el Perú recibe una puntación de 3,3, siendo que este resultado encubre algo esencial sobre cómo los peruanos participan en la política: los niveles de participación electoral son muy altos, pero la participación en las organizaciones políticas es bastante baja.

Votar es una obligación legal en el Perú cuyo incumplimiento supone pagar multas altas. El promedio de participación electoral en los comicios generales de 2001, 2006 y 2011 fue del 83\% de la población en edad de votar. En la elección presidencial de 2011 participó el $86 \%$ de la población en edad de votar, el tercer porcentaje más alto en América Latina, después de Uruguay y Ecuador, según el Institute for Democracy and Electoral Assistance (IDEA) ${ }^{5}$. El 91,5\% de las peruanas y el 89,7\% de los peruanos (90,6\% entre todos) manifestaron que acudieron a votar en 2011, el nivel más alto de América Latina en la encuesta de LAPOP. Desde 2001 los peruanos han votado 11 veces en elecciones presidenciales, legislativas, regionales, provinciales, distritales, referéndum y para el Parlamento Andino, y algunos han votado además en elecciones de revocatoria de autoridades y en las nuevas elecciones para reemplazar a las autoridades revocadas. Desde el punto de vista de las elecciones la participación política en el Perú es excelente.

La perspectiva es otra cuando se trata de la participación en organizaciones políticas, que está entre las más bajas de América Latina. En 2008 y 2010, el índice de participación fue del 5,2\% y del 6,1\%, respectivamente, superando la participación de cinco países de América Latina, según LAPOP. Para 2012 el índice había bajado al 3,2\%, superando solo a dos países (Chile y Costa Rica). Casi el 93\% de los peruanos encuestados dijeron que nunca asisten a las reuniones de los partidos o movimientos políticos, y menos del $2 \%$ asisten a reuniones de este tipo más de una o dos veces al año.

En términos comparativos, la participación de los peruanos en sus comunidades por medio de organizaciones religiosas, asociaciones de padres y madres de familia y de juntas vecinales cae entre los extremos de muy alta participación electoral a una muy baja participación en las organizaciones políticas. El 27,9\% de los 
Fig. 05 - La participación política en el Perú, 2012

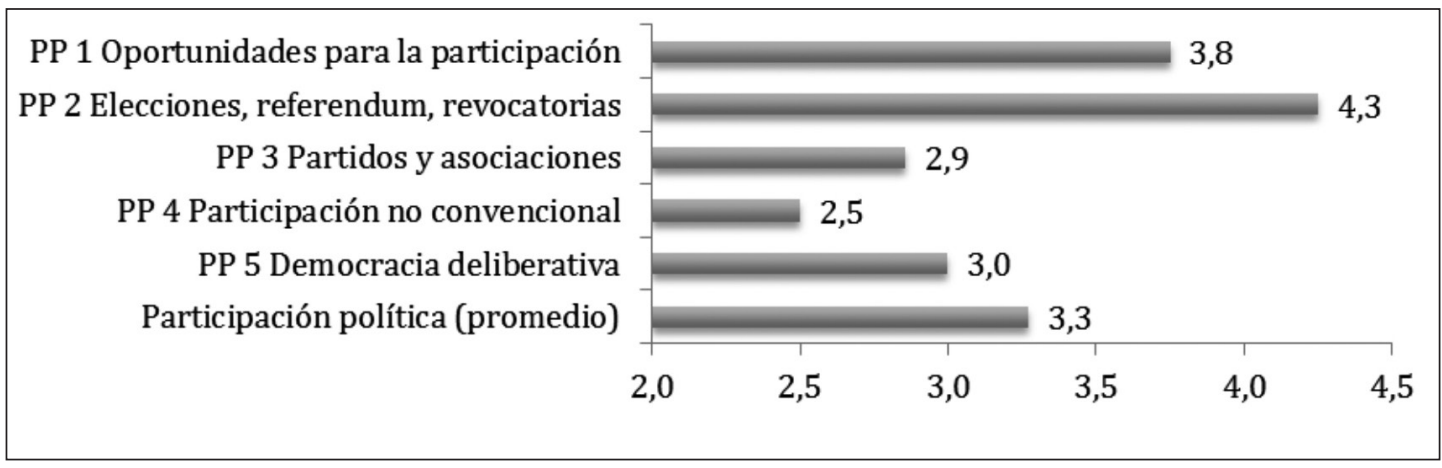

Fuente: Elaboración propia

Fig. 06 - El imperio de la ley en el Perú, 2012

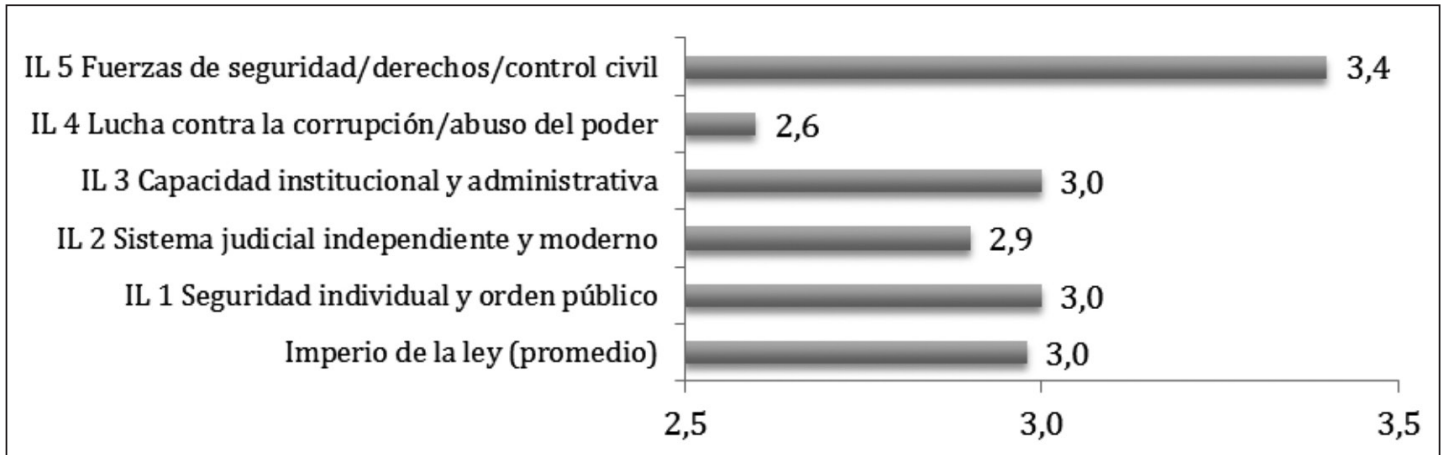

Fuente: Elaboración propia

peruanos entrevistados en 2012 indicaron que habían asistido a una reunión de la comunidad por lo menos una vez durante el año anterior (Carrión et al, 2012: 39). Esto ubicó al Perú justo por encima del promedio de América Latina, que era del 26,6\%.

En cuanto a los gobiernos locales, la participación en reuniones municipales había llegado hasta casi el 15\% en 2006 (sólo la República Dominicana y Bolivia tenían más), pero desde entonces la participación en reuniones municipales ha bajado hasta alcanzar el 12\% en 2012 (Carrión et al, 2012: 127). Esto también ubica al Perú ligeramente por encima del promedio de América Latina, que era del 10,4\%.

Desde 2002 Perú ha vivido un proceso de descentralización con la creación y elección de gobiernos regionales, y esto creó nuevas oportunidades de participación. De hecho la proporción de la población, en edad para votar, que participa en las elecciones presidenciales ha ido en aumento, del 79\% al 83\% y del 83\% al $86 \%$, según IDEA, pero como ya señalamos antes, la participación en reuniones municipales y en los procesos participativos para la formulación de los presupuestos municipales ha bajado, así que no podemos hablar de un aumento general de la participación política.

Otra forma importante de participación política es la asistencia a manifestaciones o marchas de protesta. La participación en protestas se mantuvo entre el $12 \%$ y el 13\% entre 2010 y 2012, siendo el Perú, en ambos años, uno de los países con más alta participación en protestas de América Latina (Carrión et al, 2012: 157).

En resumen, el Perú tiene niveles muy altos de participación electoral y en protestas, un nivel muy bajo de participación en reuniones de las organizaciones políticas y niveles cerca del promedio de los países latinoamericanos en asistencia a reuniones municipales y a reuniones de las organizaciones religiosas, educativas y juntas vecinales. Quizás es por esta combinación de participación alta, baja y media que cuando se les ha preguntado a los peruanos, ¿qué le falta a la democracia en el Perú?, el 31\% ha dicho que le falta participación ciudadana, un porcentaje exactamente igual al promedio latinoamericano ${ }^{6}$.

\section{El imperio de la ley}

Entre las ocho dimensiones de la calidad democrática en el Perú, una de las puntuaciones más bajas (3,0 de 5,0$)$ corresponde al imperio de la ley.

Las sub-dimensiones en peor situación son las correspondientes a la lucha contra la corrupción y el abuso del poder y a un sistema judicial independiente y 
eficaz. Otra muy problemática y de gran importancia para el público es la de la seguridad individual y el orden público. En cambio, la sub-dimensión de fuerzas de seguridad recibe una puntuación relativamente alta por el nivel de control civil, pero puntuaciones más bajas por el respeto a los derechos ciudadanos y la opinión pública. En cuanto a lo último, el nivel de confianza en la policía en el Perú (30\% en 2011) se ubicaba cerca del promedio de América Latina (33\%), mientras que la confianza en las fuerzas armadas (42\%) estaba un poco por encima del promedio latinoamericano (39\%), según Latinobarómetro.

La percepción de la corrupción es uno de los factores que más afecta al nivel de apoyo ciudadano al sistema político (Carrión et al, 2012). Perú tiene problemas muy graves con la corrupción y el abuso de poder, pero también cuenta con instituciones que han comenzado a demostrar capacidad para combatir la corrupción. Según el Banco Mundial, el Perú se ubica en sexto lugar entre 20 países latinoamericanos en cuanto al control de la corrupción ${ }^{7}$. De acuerdo con Transparencia Internacional, la percepción de la corrupción en el Perú mereció una puntuación de 38 (de 100), justo en el promedio de los países latinoamericanos que variaba entre 72 (Chile y Uruguay) y 19 (Haití y Venezuela $)^{8}$. Hay algunas indicaciones de que los peruanos se muestran poco tolerantes con la corrupción, ya que preguntados en 2011 si es aceptable pagar una coima a un funcionario público si ésta es la única manera de obtener las cosas, sólo el 15\% dije que estaba de acuerdo, colocándose así en el tercer lugar menos tolerante de las coimas en América Latina, según Latinobarómetro. Una pregunta parecida realizada por LAPOP en 2012 tuvo casi el mismo resultado en términos porcentuales (14\% dijeron que pagar una coima es a veces justificado), y esto ha bajado notablemente desde 2006 cuando fue el 22\%, pero los datos de LAPOP todavía ubican al Perú por debajo del promedio para América Latina (16\%) en el rechazo a la corrupción (Carrión et al, 2012: 86).

En la última década los peruanos han señalado constantemente a la corrupción como uno de los tres problemas más importantes del país, llegando a ser el primer problema en 2008 y 2010 (Apoyo y Mercado, años 2010, 2012 y 2013). El índice de percepción de corrupción de LAPOP en 2012 era del 76,9, y al 28,5\% de los encuestados se les había exigido un soborno dentro del último año, siendo así el Perú el quinto país más corrupto de América Latina con cierta variación de año en año, pero sin una reducción persistente significativa. La alta victimización y la percepción de corrupción en el Perú afectan seriamente a la calidad de la democracia en su dimensión del imperio de la ley.
Una de las instituciones percibidas como más corruptas en el Perú es el Poder Judicial (44\%), junto a la Policía Nacional y al Congreso (ambos con 47\%, según Apoyo y Mercado, enero de 2013). Solamente el 17\% expresaba confianza en el Poder Judicial en 2011, la segunda más baja de América Latina según Latinobarómetro (el promedio fue del 29\%). El LAPOP también encontró que la confianza en el sistema de justicia fue la segunda más baja de América Latina en 2010, algo que mejoró ligeramente en 2012 cuando fue la tercera más baja. Desde hace tiempo el Poder Judicial ha sido visto como uno de los actores políticos y económicos de importancia en el país que son menos independientes (Feld y Voigt, 2003), y los esfuerzos de reformar al sistema de justicia no han sido muy eficaces hasta ahora.

El problema de la percepción de inseguridad merece un comentario mayor, ya que es uno de los factores que más afecta al apoyo de los ciudadanos al sistema político (Carrión et al, 2012: 97). El índice de integridad fisica de Cinagrelli y Richards (CIRI) le da al Perú la puntuación de 5 en una escala en la que 0 significa ninguna protección por parte del gobierno contra tortura, ejecución extrajudicial, desaparición forzada y encarcelamiento político y 8 significa máxima protección. Así, el Perú se ubica ligeramente por encima del promedio para América Latina. Pero este índice es de poca utilidad para medir la inseguridad de los ciudadanos cuando ésta proviene principalmente de grupos de delincuentes, y no del Estado.

Hasta el año 2006, el porcentaje de peruanos que consideraba que la delincuencia era el problema principal del país no pasaba del $2 \%$; el desempleo era el más importante para el 30-40\% de la población. Esto comenzó a cambiar en 2006, y en 2011 el porcentaje que consideraba que la delincuencia era el problema principal del país (20\%) superó por primera vez a los que pensaban que el desempleo era el más importante (19\%), según Latinobarómetro. En 2012, la brecha aumentó significativamente con el $28 \%$ de los encuestados señalando a la delincuencia/falta de seguridad como el problema que más les afectaba personalmente, mientras que el porcentaje correspondiente al desempleo/falta de trabajo cayó al 12\% (Apoyo y Mercado, mayo de 2012). En esta creciente preocupación por la delincuencia, los peruanos han alcanzado a los demás latinoamericanos, quienes también señalaron a la falta de seguridad ciudadana como problema principal en un $28 \%$ en 2011, de acuerdo con Latinobarómetro.

Hace falta clarificar varios puntos relacionados a esta apreciación. Primero, los cambios en la priorización del problema de la delincuencia son producto no solo de la incidencia de los actos delictivos, sino también de la caída en la importancia relativa de otros 
problemas como el terrorismo o la economía. El buen desempeño de la economía peruana ha llevado a una reducción del nivel de preocupación por el desempleo y los problemas económicos. Además, la priorización del problema de la delincuencia subió en el Perú sin cambios significativos en las tasas de victimización (el porcentaje de ciudadanos que dice haber sido víctima de un delito). El promedio de la tasa de victimización entre 2001-2005 fue del 40\%. Para 2006-2011 bajó ligeramente al 37\%, según Latinobarómetro, aunque otra forma de medir la victimización estimó los niveles en un promedio del 28\% entre 2006 y 2010, quedándose en el 28\% en 2012 (Carrión et al, 2012: 88). Así que la priorización del problema de la delincuencia no corresponde necesariamente a un aumento significativo de la frecuencia de los actos delictivos.

Segundo, la tasa de victimización en el Perú es mucho más alta que el porcentaje que considera a la delincuencia como el primer problema del país. En 2011, el 40\% de los peruanos dijeron que ellos, o algún pariente, habían sido víctima de un delito - un nivel de victimización superado solo por México, según Latinobarómetro. En 2012, el 44\% de los peruanos señalaron que ellos, o algún miembro de su hogar, habían sufrido un delito, y el 28\% de los peruanos dijeron que ellos mismos habían sido victimizados - el nivel más alto en América Latina (Carrión et al, 2012: 92).

Tercero, la tasa de victimización corresponde a otras percepciones, como la percepción de seguridad ciudadana: solo el $8 \%$ de los peruanos manifestó que había buena seguridad ciudadana en el Perú, el segundo nivel más bajo de América Latina en 2011 por los datos de Latinobarómetro. En 2012, el índice de percepción de inseguridad en el Perú fue de 48,6, el más alto de América Latina (Carrión et al, 2012: 88). Pero estas percepciones de inseguridad no se corresponden a otras medidas de la delincuencia, tal como la tasa de homicidios. A la vez que el Perú tenía en 2011 la segunda tasa más alta de victimización, la tasa de homicidios en el Perú fue de 5,2 por 100.000, la segunda más baja de América Latina después de Chile, según Latinobarómetro. La Oficina para las Drogas y el Crimen de las Naciones Unidas (UNODC) presenta en otra publicación datos sobre el homicidio en el Perú que coinciden con lo anterior pero sólo por un año, en el 2004 cuando la tasa fue de $5,6^{9}$.Y desde esa fecha sube significativamente la tasa de homicidios en el Perú hasta 2009, el último año reportado, de 10,3. Datos de una tercera fuente presentan un cuadro más dramático: la tasa de homicidios según la OEA coincide con UNODC para el año 2004 en 5,6 y para los años 2005-2008 y de allí se dispara a 14,0 en 2009, 18,6 en 2010, y 24,1 en 2011, el último año para los que hay datos.
Quizás esta confusión de datos es un indicador de gestión en las políticas de seguridad pública en el Perú, ya que ninguno de los datos sobre las tasas de homicidios corresponde a las tasas de victimización. Si aceptamos que la tasa de homicidios es baja y estable, sólo podríamos explicar el alto nivel de victimización en el Perú asociándola a otras variables como el papel que juegan los medios de comunicación en la construcción de estas percepciones al sobredimensionar los problemas de la violencia urbana o también se deba a otros delitos distintos como hurtos o robos, violencia intrafamiliar, etc.

Lo que sí puede afirmarse sin duda es que la percepción de inseguridad socava el imperio de la ley y que reducir la corrupción - especialmente la que marca tan profundamente al Poder Judicial y a la policía y aumentar la seguridad de los ciudadanos son tareas centrales para aumentar la calidad de la democracia en el Perú.

\section{Libertades}

Entre las ocho dimensiones de calidad democrática, la de libertades es la que se encuentra mejor evaluada para el caso del Perú. Sin embargo, en cuanto a las sub-dimensiones, encontramos significativas diferencias entre una y otra. Así por ejemplo la sub-dimensión de derechos civiles recibe una puntuación de 3,3, frente a la sub-dimensión de derechos políticos que destaca con 5,0 .

La sub-dimensión de derechos políticos en el Perú, como en muchos países de América Latina, está definida en la Constitución política. Así, todos los ciudadanos a partir de los 17 años tienen la obligación de llevar el Documento de Identidad Nacional (DNI), pero desde los 18 años adquieren el derecho y la obligación de votar en todo proceso electoral sea de naturaleza nacional, regional o municipal. Además de votar, todos los ciudadanos tienen el derecho a ser elegidos a cargos públicos, exceptuando los miembros de las Fuerzas Armadas y de la Policía Nacional. Hay que señalar que desde 2001 los procesos electorales no han sido cuestionados en cuanto a su legitimidad, tanto en lo referente al recuento de votos como a la legitimidad de quien ha sido electo.

La Constitución de 1993, aprobada en el régimen autoritario de Fujimori, aún está vigente a pesar que ha sufrido modificaciones después de la transición. Así, los derechos a la participación ciudadana se han asegurado y están regulados por el artículo 31, que señala que todos los ciudadanos pueden participar mediante referéndum, la presentación de iniciativas legislativas ciudadanas, la separación o revocatoria de las autoridades

9 Informe Mundial sobre las Drogas, UNODC, 2012. Disponible en <https://www.unodc.org/documents/ data-and- analysis/WDR2012/ Executive_summary_spanish.pdf>. 


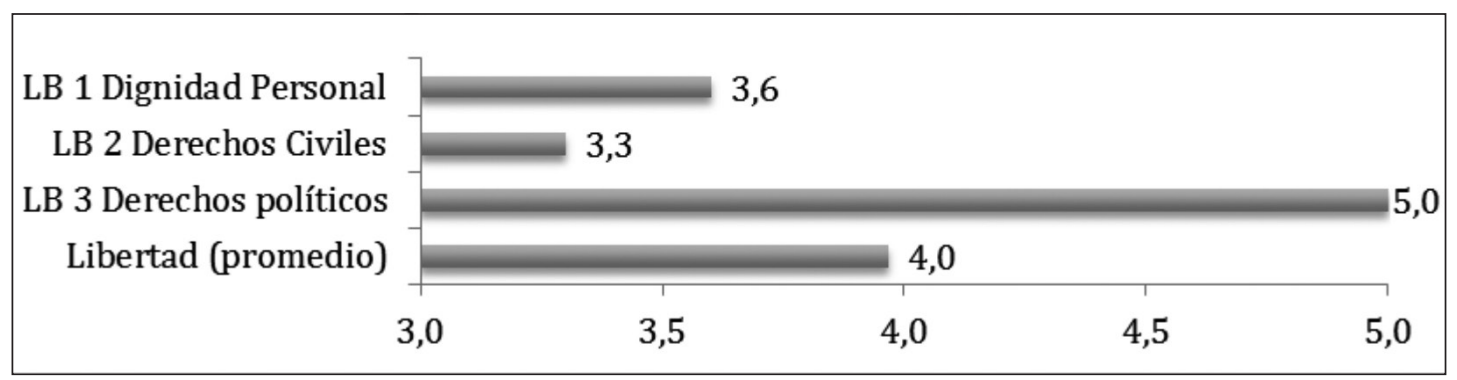

Fuente: Elaboración propia

locales, así como la demanda de rendición de cuentas de la gestión pública.

Los mecanismos de participación ciudadana han sido activados de forma e intensidad diferentes. En cuanto al referéndum, solo ha sido convocado una vez, en 2006, cuando la Asociación del Fondo Nacional de Vivienda (FONAVI) demandó vía referéndum la obligación del Estado a la restitución de sus aportaciones al fondo en anteriores décadas. No obstante, hasta el día de hoy no se ha materializado la demanda que fue aprobada mayoritariamente en esa fecha. En lo que respecta a la revocatoria del mandato de autoridades, esta solo tiene efecto en las autoridades de ámbito municipal y regional. En 2013 la ciudadanía fue convocada, en 124 distritos del país, para decidir la revocación o la permanencia en el cargo de 119 alcaldes y 471 regidores distritales, de los cuales 24 alcaldes y 164 regidores fueron revocados ${ }^{10}$.

En el caso de las iniciativas legislativas ciudadanas, estas son aceptadas siempre y cuando sean presentadas por el $0,3 \%$ de la población electoral nacional y con firmas comprobadas por la entidad electoral y se encuentran circunscritas a la intermediación del Congreso. La poca importancia se refleja en el bajo número de iniciativas legislativas presentadas hasta el día de hoy. Así sólo seis proyectos de ley se transformaron en norma, de 26 presentados desde 2001.

En el caso de la rendición de cuentas, esta no ha producido efectos concretos en la relación gobierno-ciudadano, ya sea en la divulgación de los programas gubernamentales, vía monitoreo electrónico de obras públicas, o en la misma dificultad de acceso a la información, si bien hay una serie de normas que buscan regular la transparencia. La participación ciudadana está limitada por la ausencia de información o por la falta de acceso a la misma, principalmente en los municipios más pobres o alejados del país.

En cuanto a la sub-dimensión de dignidad personal, si bien el Perú es signatario de las convenciones internacionales sobre derechos humanos, deja mucho que desear en las prácticas referidas a torturas practicadas por agentes del Estado. En el sexto informe presentado en 2011 por el Estado al Comité contra la Tortura de las Naciones Unidas ${ }^{11}$, de acuerdo con el subsistema especializado en derechos humanos del Ministerio Público, desde el año 2003 a mayo del 2011 se han presentado denuncias sobre 343 casos de tortura, de los cuales en 105 casos los presuntos responsables eran miembros del Ejército Peruano (EP) y en 106 casos los presuntos responsables eran miembros de la Policía Nacional del Perú (PNP). Como señala también el informe de los 343 presuntos casos de tortura, 142 se encuentran archivados definitivamente, 35 archivados provisionalmente; 30 con formalización de denuncia, 78 en investigación y 58 en calidad de derivados.

En lo referido a los derechos civiles, que es la sub-dimensión más crítica, podemos identificar la ausencia de políticas públicas concretas que protejan los derechos de las minorías. Aunque existe una clara protección normativa, se produce una disociación en la aplicación real de los derechos, sobre todo en el caso de las minorías que defienden su orientación sexual e identidad de género. Para estas minorías prácticamente no existen políticas públicas concretas.

El Informe Anual sobre Derechos Humanos de Personas Transexuales, Lesbianas, Gays y Bisexuales en el Perú, de 2012, denuncia la negligencia del Estado para tomar medidas que sirvan para procesar y condenar la violencia contra estos grupos ${ }^{12}$. Así el Movimiento Homosexual de Lima (MOHL) reportaba que

10 Informe de resultados: nuevas elecciones municipales y segunda consulta popular de revocatoria del mandato de autoridades municipales de julio de 2013, Oficina Nacional de Procesos Electorales (ONPE), Perú, 2013. Disponible en <http://www.web.onpe.gob.pe/modEscaparate/ downloads/L-0089.pdf>.

11 Examen de los informes presentados por los Estados partes con arreglo al artículo 19 de la Convención, Comité contra la Tortura de las Naciones Unidas, 2011. Disponible en <http://www2.ohchr.org/ english/bodies/cat/docs/CAT.C.PER.6_sp.pdf>. Acceso en 20 de diciembre de 2013. 12 Informe Anual sobre Derechos Humanos de Personas Transexuales, Lesbianas, Gays y Bisexuales en el Perú, 2012. Disponible en <http:// promsex.org/images/docs/Publicaciones/informetlgb2012.pdf>. Acceso en 17 de diciembre de 2013. 
Fig. 08 - La responsabilidad y la legitimidad en el Perú, 2012

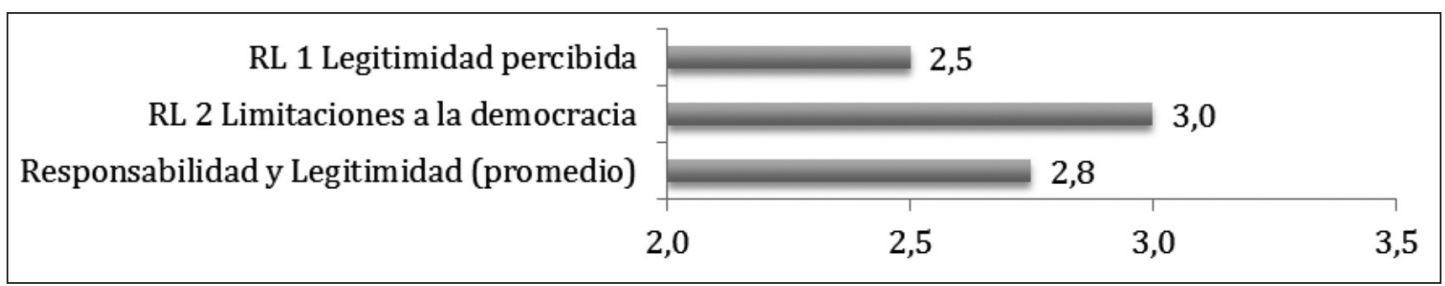

Fuente: Elaboración propia

249 personas homosexuales fueron asesinadas entre 2006 y 2010.

También los diversos grupos étnicos del Perú sufren la ausencia de políticas públicas de reconocimiento de sus derechos. Así el racismo y la discriminación son la expresión invisible de la violencia para la que no existen datos cuantitativos, ya que esta se ejerce principalmente en espacios privados. Sin embargo el Estado ha permitido la naturalización de este tipo de violencia y que se conozca por medio de los medios de comunicación, contribuyendo con ello a vulnerar abiertamente los derechos colectivos de los diversos grupos afectados. La violencia de género es alarmante en el país, según encuesta del Instituto Nacional de Estadística e Informática (INEI), que señala que por lo menos el 37,2\% de las mujeres entre 15 y 19 años ha sufrido alguna vez violencia física o sexual, concentrándose el registro en los departamentos de Cuzco, Apurímac, Ayacucho, Loreto y Huancavelica, lo que implica inferir que este tipo de violencia afecta sobre todo a las mujeres indígenas, pobres, analfabetas y, generalmente, sin acceso a servicios de salud o de orientación jurídica para la defensa de sus derechos.

\section{Responsabilidad}

El Perfil del Elector elaborado por el Jurado $\mathrm{Na}-$ cional de Elecciones en 2010 mostraba que el 67\% de los electores peruanos manifestaba el muy poco o ningún interés por la política. Este índice ha crecido en 2014, cuando el 77,9\% de los peruanos manifestaba que poco o nada le interesa la política, según LAPOP. Con relación a la democracia, encuestas recientes presentan datos que generan preocupación. En 2014, los que opinaron sobre la democracia como mejor sistema de gobierno llegaron al 71\% entre los peruanos, mientras que en 2015, el número de peruanos que lo consideraban así bajó al 53\%, muy próximo al 58\% de los ciudadanos que han manifestado un sentimiento de insatisfacción con la democracia, según la encuestadora GFK Perú.

La confianza de los peruanos en sus instituciones cada vez más se muestra alarmante para un país que busca superar el retroceso autoritario de la década de los 1990. El 72\% de la ciudadanía desaprueba la labor desempeñada por el Congreso, un 76\% desaprueba la labor del Poder Judicial, y el Ejecutivo liderado por el presidente Ollanta Humala ha llegado en 2015 a 79\% de desaprobación, según GFK Perú. La percepción de que a los que gobiernan poco les importa lo que piense la gente se refleja en el 62\% de ciudadanos que están de acuerdo con esta afirmación. Por datos como estos, el Perú recibe una de sus puntuaciones más bajas $(2,8$ de $5,0)$ en la dimensión de responsabilidad y legitimidad.

Entre los factores que contribuyen a los bajos niveles de confianza en las instituciones democráticas en el Perú, consideramos como los más importantes: los efectos perniciosos del sistema de representación, el desarraigo de los partidos políticos, la poca efectividad de los controles institucionales en la gestión pública, la percepción negativa hacia los políticos y la política y, de forma indirecta, el papel de los medios de comunicación.

Un ejemplo se visualiza en el discurso del régimen autoritario contra el bicameralismo que primó a inicios de la década de los 1990 y que usó para justificar la quiebra del orden constitucional. Este discurso tuvo cierta influencia en los actores que asumieron el control de la transición política a principios del 2000 , pero dentro del clima de indecisión propio de un contexto de cambio se decidió no convocar una Asamblea Constituyente y solo reformar la Constitución. De esa forma se continuaría con el formato unicameral de representación, figura instituida por el gobierno autoritario en la Constitución de 1993, manteniendo el número de congresistas en 120 hasta el año 2009, cuando se incrementó en 10 el número de escaños. No obstante, aún es posible observar los efectos, después de tres elecciones presidenciales, de no haber realizado una reforma política.

Hubo sí modificaciones de la ley electoral. En la década de los 1990 los parlamentarios eran elegidos con la fórmula del distrito electoral único. A partir del 2001 pasaron a ser electos bajo el distrito electoral múltiple, dividiéndose el país en 25 distritos. Cada departamento es una circunscripción electoral, creándose para las elecciones de 2011 una circunscripción más, la de Lima-provincias, y estableciéndose la barrera del 5\% de los votos válidos a nivel nacional para que un partido pueda elegir congresistas.

El "peso político" así como los "costes" para elegir un representante difieren substancialmente entre la capital y los departamentos del interior. Un ejemplo de ello se ve cuando se compara el departamento de 
Madre de Dios y Lima. El padrón electoral del departamento de Madre de Dios estaba compuesto por 71.279 electores que deben elegir tres congresistas, cada congresista, por lo tanto, representaría a 23.759 electores, mientras que en Lima, que tenía 6.745.985 electores y elige 36 congresistas, cada congresista teóricamente representaría a 187.388 ciudadanos, lo que nos llevaría a concluir que existe una sub y/o sobre-representación significativa en los distritos electorales.

La literatura que trata sobre los problemas de malapportionment ${ }^{13}$ se refiere a las distorsiones que se producen a cuenta de la sub o sobre-representación electoral en los distritos. Dada la relación entre el número de escaños por distrito y la población electoral relativa del distrito, se observa que la sobre-representación vendría a ser la regla en América Latina, con excepción de Perú (Reynoso, 2002). La sobre-representación es una distorsión congénita de la técnica de representación, dada la imposibilidad matemática que resulta de dividir la representación en partes exactamente proporcionales entre la cantidad de electores de cada distrito. Estas distorsiones evidencian que cuanto menos escaños le correspondan a una circunscripción electoral, menos posibilidades tienen los partidos pequeños de obtenerlos (Samuels, 2000).

Desde esa perspectiva, el Perú es una excepción, pues su índice de malapportionment es igual a 0 , mientras que en los demás países latinoamericanos el promedio es de 8,6 (Bunker y Navia, 2010). La razón para que esto sea así es por el formato unicameral del Congreso. Sin embargo, el problema es mucho más complejo si consideramos que en el caso peruano se cumple el principio democrático de "una persona, un voto" discutido por Dahl (1989) viendo que el nivel de representatividad de los distritos electorales es bastante simétrico. Si bien no existe sobre-representación de un distrito en relación a los otros, si se puede identificar una significativa sub-representación de los distritos.

Para hacer viable un orden político representativo territorialmente, hay que incrementar la representación en los territorios de baja concentración demográfica, como es el caso de los departamentos amazónicos. Por ejemplo, el de Ucayali elige dos congresistas en un universo de 26.938 electores. Si se observa que la mayor concentración demográfica se encuentra en la provincia de Coronel Portillo con el $77,2 \%{ }^{14}$, esto significa que las otras como Padre Abad (11,7\%), Atalaya (10,2\%) y Purus $(0,9 \%)$ no tendrían ninguna probabilidad de elegir un representante. En otras palabras hay grandes extensiones de territorio en el Perú que sufren de una significativa sub-representación, cuestión que debe llevar a reflexionar sobre la magnitud de los distritos electorales en el país.

En el ámbito sub-nacional el desarraigo de los partidos políticos en el Perú expresa el desencajamiento y la baja expansión del sistema nacional de partidos en los subniveles regional, provincial o municipal. Aunque las dinámicas en estos subniveles tienen unas características propias, también existe un fenómeno inverso, la expansión de partidos de base local en dirección a niveles más complejos y que requieren mayor articulación, como lo serían las plataformas políticas de carácter provincial, regional y nacional.

La fragilidad de los movimientos regionales puede ser mucho mayor que la de los partidos políticos de ámbito nacional, ya que estos movimientos, organizaciones o plataformas no han conseguido transcender de sus propias circunscripciones y están construidos bajo la misma lógica que los partidos nacionales con la diferencia de que los primeros son efímeros, presentando un sistema de partidos regionales, provinciales y municipales de mayor volatilidad. Pero, ¿por qué la tendencia de baja expansión de los partidos de ámbito nacional hacia los espacios regionales, provinciales o municipales?

Este fenómeno comienza a producirse antes de las elecciones regionales de 2002, cuando, iniciada la transición política, por ley se convocó un proceso para elegir representantes cuyas funciones prácticamente eran desconocidas por la ciudadanía (Remy, 2010). Ante este nuevo y confuso espacio electoral el partido mejor organizado era el APRA que, en medio a un sistema de partidos fragmentado, consiguió 12 de los 25 gobiernos regionales, mientras que Perú Posible, partido que había resultado victorioso en las elecciones presidenciales de un año antes, sólo conquistó un gobierno regional.

Las elecciones presidenciales siguientes se realizaron en abril de 2006, y las regionales, en noviembre de ese mismo año. Los resultados en las dos contiendas preocuparon a los partidos políticos. Alan García, del Partido Aprista, que había triunfado en seis regiones en las elecciones presidenciales y sido elegido, casi desaparece del mapa electoral en las elecciones regionales, consiguiendo retener sólo dos gobiernos regionales, mientras que su adversario principal Ollanta Humala, del Partido Nacionalista, que había triunfado en 18 regiones en las elecciones presidenciales, no ganó ningún

13 La malapportionment es medida por el índice de desproporcionalidad de Loosemore y Hanby (1971), pero sufrió una variación que en vez de calcular la diferencia entre el número de votos y escaños de un partido, se establece la diferencia entre el porcentaje de electores de un distrito y el porcentaje de escaños que se eligen en el mismo distrito siendo la fórmula: $M a l=\frac{1}{2} \sum(\% \mathrm{~S} 1-\% \mathrm{~V} 1)$, donde \% $\mathrm{S} 1$ es el porcentaje de escaños,
y \% 1 , el porcentaje de votantes.

14 Censos Nacionales 2007: XI de Población y VI de Vivienda, Instituto Nacional de Estadística e Informática (INEI), Perú. Disponible en <http:// www.inei.gob.pe/biblioineipub/bancopub/Est/Lib0838/libro11/Libro.pdf>. 
gobierno regional cinco meses después. Un fenómeno parecido ocurrió en las elecciones regionales de 2010. El Partido Nacionalista sólo ganó el gobierno regional de Cuzco, mientras que en la elección presidencial de 2011 Humala triunfó en 17 circunscripciones regionales y se eligió.

Es importante recordar que hubo cambios en las reglas electorales para las elecciones regionales. El candidato podía ganar con mayoría simple y conseguía automáticamente mayoría en el consejo regional, creándose una sobre-representación de movimientos que ganaron con una bajísima cantidad de votos, como es el caso del presidente regional de Puno, que ganó la elección en 2006 con el 19\% de los votos. Para las elecciones de 2010 se estableció la regla de que si un candidatos no conseguía superar el 30\%, los dos primeros disputarían una segunda vuelta, mientras que los consejeros regionales eran elegidos bajo el sistema mayoritario teniendo a las provincias como distrito único.

$\mathrm{La}$ transferencia de recursos y competencias a las regiones fue generando una intensa dinámica entre políticos locales que comenzaron a ocupar un espacio político caracterizado por una demanda históricamente reprimida de participación en las regiones. Este nuevo espacio de disputa electoral fue a su vez estimulado por la facilidad de inscribir plataformas electorales. Todo ello lo que ha provocado es la multiplicación de organizaciones que buscan hacerse con el gobierno local y que optan por reproducir la lógica nacional de competencia de elecciones centrada en el candidato. Esta dinámica prácticamente de carácter centrifuga configura una dispersión significativa del voto, invisibilizando a los partidos de ámbito nacional.

La lógica del sistema electoral centrado en el candidato pasó del ámbito nacional al regional y a los siguientes subniveles. De esa forma los políticos en el ámbito regional encontraron una salida menos complicada al evitar "amarrarse" a una estructura partidaria nacional, haciéndolos más eficientes en la disputa electoral dada su estructura laxa frente a una estructura rígida de los partidos nacionales, que presentan de alguna forma controles intra partidarios. Además, los políticos regionales no están circunscritos a cuestiones programáticas ni mucho menos tienen interés por mantener una estructura partidaria permanente que les genere costes.

La poca atracción hacia los partidos nacionales ha provocado una seria dificultad para instalarse en el ámbito regional, provincial o municipal. No obstante, los partidos nacionales encuentran en los movimientos regionales aliados transitorios en elecciones presidenciales, que son reclutados sobre la base de su reputación personal, cantidad de recursos del candidato a presidente y la densidad social de su plataforma regional.

Sin embargo, uno de los más importantes problemas del sistema de representación en el Perú es su elevada desproporcionalidad, que repercute en términos de alteraciones de la voluntad popular materializada en las urnas y con ello la exclusión de una parte importante del electorado. Si el índice de malapportionment mide las distorsiones entre el porcentaje de población y los escaños, la desproporcionalidad mide las distorsiones entre el porcentaje de votos y los escaños.

Un principio fundamental de la proporcionalidad sería la correspondencia exacta entre votos y escaños que obtienen los partidos en las elecciones. Aunque empíricamente no existe la proporcionalidad perfecta, en todo caso el objetivo de este formato es el de maximizar la representación y reducir el número de electores "nulos". El problema es la acentuada desproporcionalidad en el Perú, que contribuye a crear una representación artificial o sustentada en el vacío, una percepción de mayor distanciamiento entre representación política y voluntad ciudadana, así como un déficit en la intermediación y/o agregación de los diversos intereses sociales.

Para identificar el grado de desproporcionalidad ${ }^{15}$ en términos de cómo fue repartida la cantidad de escaños de acuerdo con los votos, en el gráfico siguiente se verifican tres situaciones importantes. La primera expresa que la desproporcionalidad disminuyó en las elecciones presidenciales de 2011, debido a la creación de la circunscripción Lima-Provincias y al incremento de 10 congresistas. Esto hace necesario pensar en un nuevo rediseño de las circunscripciones electorales, así como el incremento del número de congresistas, para ajustar mejor el reparto de escaños a la distribución de votos.

Cabe anotar que la magnitud de la circunscripción es un elemento central al analizar los indicadores de proporcionalidad (Lijphart, 1994; Taagepera y Shugart, 1989). Sin duda esto se debe a que la proporcionalidad está asociada no sólo con la forma de conversión de votos en escaños sino también con la magnitud de la circunscripción electoral. De esa forma rediseñar las circunscripciones no sólo buscaría resolver un simple problema de distribución perfecta o de proporcionalidad, tiene que ver principalmente con criterios para buscar dar mayor legitimidad a la representación política, así como convertir la democracia en un sistema fundamentalmente inclusivo.

El índice de desproporcionalidad en Perú es elevado si lo comparamos con otros países latinoamericanos, por ejemplo el índice promedio de la desproporcionalidad

15 El least-squares index (Lsq) propuesto por Gallagher (1991) y usado por Lijphart (1994) permite estimar la desproporcionalidad del sistema electoral a partir de las diferencias entre los porcentajes de votación (Vi) y la adjudicación de escaños $(S i): L s q=\sqrt{\Sigma} \frac{1}{2}(\text { Vi.Si })^{2}$ 


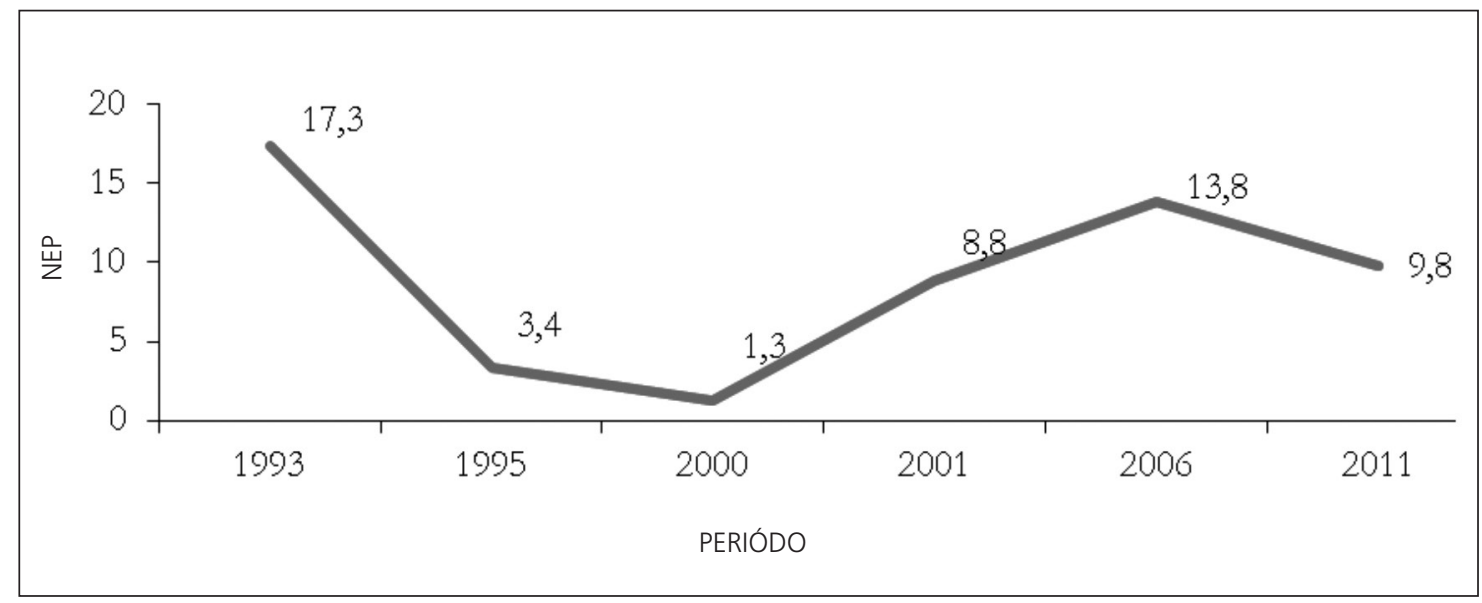

Fuente: Elaboración propia

entre 1990 y 2002 en Argentina fue de 6,7, mientras que entre 1990 y 2006 en Colombia fue de 6,5. El Perú sólo es menos desproporcional que Guatemala y Panamá, quienes lo superan con 11,9 y 13,9 (PNUD, 2004), respectivamente, siguiéndole el Perú como el tercer país más desproporcional de América Latina con un promedio entre 1993 y 2011 de 9,1. Esto evidencia que la no correspondencia entre votos y escaños es bastante significativa y que produce una distorsión profunda de la voluntad popular.

Podemos identificar una significativa distorsión asociada a la desproporcionalidad y que tiene que ver con el porcentaje de votos válidos de los partidos para el Congreso y el porcentaje de escaños que representan, lo que en Perú no se corresponde, o en todo caso es elevada la desproporcionalidad, provocando efectos negativos de sobre-representación y sub-representación parlamentaria como se puede apreciar en el siguiente cuadro.
Si se analiza la diferencia entre el porcentaje de votos emitidos de los dos partidos con mayor votación al Congreso en 2011, que son Gana Perú y Fuerza 2011, y el porcentaje de escaños que obtuvieron, se observa que en 2001 los dos partidos más importantes obtuvieron en conjunto una ventaja favorable del $24 \%$, en 2006, incluso con la aplicación de la barrera electoral, la sobre-representación se elevó al 25,8\%, y en 2011 la tendencia a la sobre-representación se confirmó con el $27 \%$.

\section{Igualdad}

Según Latinobarómetro, la imagen entre los peruanos de que el país está progresando cayó entre 2011 y 2013 del 49\% al 41\%. Resulta paradójico que en éste último año sólo el 22\% consideraba que su situación personal era muy buena. Cabe recordar que el progreso material del

Tabla 1 - Sobre-representación y sub-representación en el Congreso del Perú en las elecciones de 2011

\begin{tabular}{|l|c|c|c|c|}
\hline \multicolumn{1}{|c|}{ Partido político } & $\begin{array}{c}\% \text { de votos } \\
\text { recibidos }\end{array}$ & $\begin{array}{c}\text { \% de representación } \\
\text { en el Congreso }\end{array}$ & $\begin{array}{c}\text { Número } \\
\text { de escaños }\end{array}$ & Representación real \\
\hline \multicolumn{5}{|c|}{ Sobre-representación } \\
\hline Gana Perú & $19,4 \%$ & $36 \%$ & 47 & $+16,6$ \\
\hline Fuerza 2011 & $17,6 \%$ & $28 \%$ & 37 & $+10,4$ \\
\hline Perú Posible & $11,4 \%$ & $16 \%$ & 21 & $+4,6$ \\
\hline \multicolumn{7}{|c|}{ Sub-representación } \\
\hline Alianza por el Gran Cambio & $11 \%$ & $9 \%$ & 12 & -2 \\
\hline \multicolumn{7}{|c|}{ Relativa Proporcionalidad } & 9 & $-0,8$ \\
\hline Alianza Solidaridad Nacional & $7,8 \%$ & $7 \%$ & 4 & $-1,9$ \\
\hline Partido Aprista Peruano & $4,9 \%$ & $3 \%$ & \\
\hline
\end{tabular}


Gráfico 03 - \% de votación y \% de escaños obtenidos por las dos agrupaciones mayoritarias en el Congreso 1993 - 2011

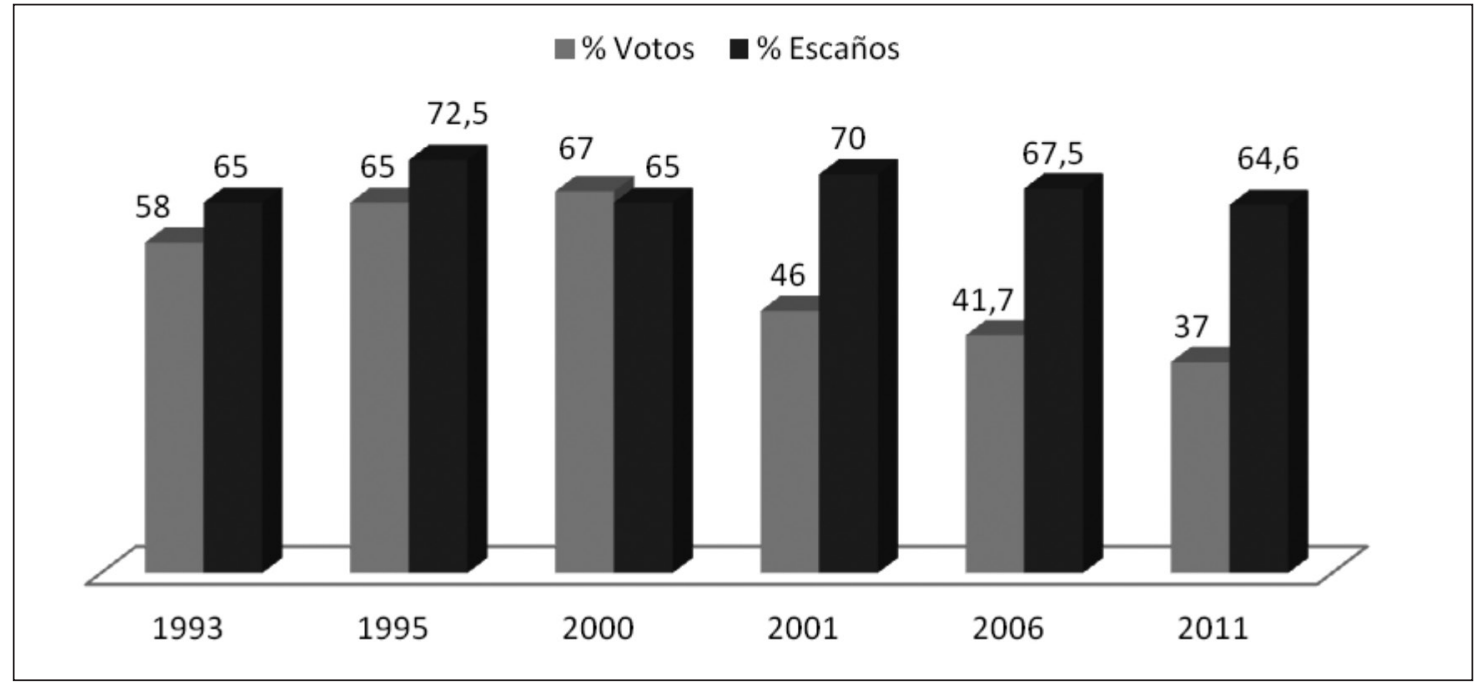

Fuente: Elaboración propia

país está asociado a los indicadores macroeconómicos más importantes, como es el crecimiento del PIB que en los últimos nueve años llegó a una media de 6,8\%. Los indicadores sociales referidos a la disminución de la pobreza también ofrecen alentadores avances, ya que la pobreza siguió una tendencia de caída constante, en 2007 fue del 42,4\%, en 2010 decreció al 30,8\%, para pasar al 25,8\% en 2012 y al $22,7 \%$ en $2014^{16}$, siendo que las áreas de mayor persistencia y concentración de la pobreza se encuentran todavía en las zonas rurales. De todos modos, el Perú recibe su puntuación más baja (2,3 de 5,0) en la dimensión de igualdad y solidaridad.

En cuanto al indicador de desigualdad, el INEI muestra que entre 2004 y 2012 pasó del 0,41 al 0,36, lo que indica que la desigualdad ha disminuido significativamente. Según el Banco Interamericano de Desarrollo (BID), la clase media pasó entre 2005 y 2014 del 25,9\% al 50,6\%, aunque el 33,6\% de este último porcentual es clase media emergente que estaría en situación de vulnerabilidad con la perspectiva de retornar a ser pobre.

De acuerdo con un informe del INEI $^{17}$, el 44,1\% de los pobres del Perú participa del mercado laboral como trabajadores independientes, el 29,9\% como asalariados, el 22,4\% como trabajadores no remunerados, el 1,9\% como patronos y el 1,7\% como trabajadores del hogar. En cuanto a la población ocupada no pobre, el 51,5\% es asalariado (empleados y obreros), el 32,8\%, trabajadores independientes, el 8,5\%, trabajadores familiares no remunerados, el 5,1\%, patronos o empleadores, y el 2,2\%, trabajadores del hogar.

En la garantía del acceso al seguro de salud, se evidencia que existen diferencias entre pobres y no pobres. Así, de cada 100 pobres, 80 tienen acceso al Seguro Integral de Salud (SIS), mientras que en el caso de los

Fig. 09 - La igualdad y la solidaridad en el Perú, 2012

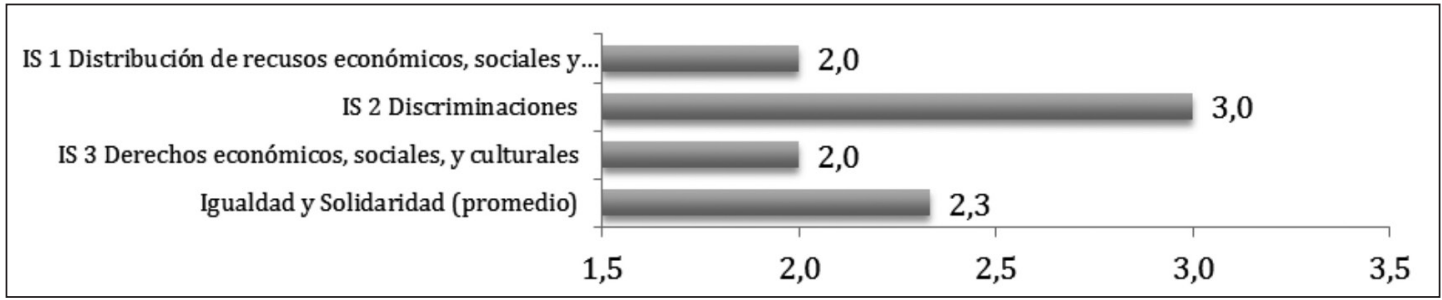

Fuente: Elaboración propia

16 Encuesta Nacional de Hogares 2009-2014, Instituto Nacional de Estadística e Informática (INEI), Perú. Disponible en <http://www.inei.gob.pe/ media/cifras_de_pobreza/informetecnico_pobreza2014.pdf>

17 Informe Técnico sobre la Evolución de la Pobreza Monetaria 2009-2014, INEl, Perú. Disponible en <http://www.inei.gob.pe/media/cifras_de_ pobreza/informetecnico_pobreza2014.pdf>. 
no pobres el número se reduce a 30 de cada 100. Estas cifras no evidencian la baja calidad de los servicios de salud prestados.

En el caso de la educación, se registra que el 48,4\% de los pobres sólo logró estudiar algún año de educación primaria o no tenía nivel alguno de educación. En el segmento de los no pobres el cuadro no deja de ser preocupante, ya que el 20,9\% apenas alcanzó la primaria, mientras que sólo un 44,6\% alcanzó estudios de secundaria.

Con algunos indicadores positivos de la economía y una clara muestra de ascensión social en los últimos años, existe un significativo sentimiento de malestar, ya que el crecimiento parece no llegar al bolsillo de los propios peruanos. Una explicación de este malestar puede deberse a la baja estabilidad en la contratación de mano de obra, dado que la política de flexibilización laboral no ha garantizado la mejoría de millones de peruanos. La informalidad domina dentro de la propia Población Económicamente Activa (PEA). Según el INEI, solo 4,5 millones de trabajadores se encuentran sujetos a las leyes laborales dentro de una población de personas en edad de trabajar de 21,3 millones.

Si bien la tasa de desempleo nacional (urbano y rural) en Perú pasó del 9,5\% en 2005 al 5,8\% en 2011, hay que recordar que uno de los problemas más graves es la baja remuneración, la misma que desde 2012 no ha mejorado, la misma que podría ajustarse de acuerdo a la inflación acumulada desde esta fecha, y la misma que debe garantizar la subsistencia del trabajador así como su protección social. Estas condiciones contribuyen a generar bajas expectativas en los trabajadores, sobre todo en un país donde los sindicatos no tienen peso político significativo.

Por otra parte, si bien existe una política de control macroeconómico de la inflación que ha permitido el incremento de la capacidad adquisitiva de los trabajadores, el mercado aún no está disponible para un segmento mayoritario de los peruanos y mucho menos para los pobres, dada el bajo acceso al crédito y con ello las limitaciones del consumo. Además, las políticas asistenciales o de incentivos para acceder al empleo aún son poco consistentes y de baja efectividad, ya que no agregan porcentajes significativos de la población en edad de trabajar.

Otro elemento que afecta a las relaciones de igualdad/solidaridad es la discriminación racial, como hemos mencionado anteriormente, siendo uno de los problemas más serios que enfrenta la sociedad peruana. Aunque existen leyes que prohíben la discriminación racial y étnica, en la realidad estas no se aplican. Numerosos grupos humanos sufren una serie de desventajas en el Perú, como las mujeres indígenas o los afro-descendientes. Las mujeres indígenas, por ejemplo, son las que más sufren de indocumentación; los jóvenes indígenas son el grupo más reclutado para el servicio militar; y los afro-descendientes y las personas de rasgos andinos son los grupos que más trabajan en el sector informal. Un informe al Comité para la Eliminación de la Discriminación Racial de las Naciones Unidas (CERD) denuncia por ejemplo que:

\begin{abstract}
"Las mujeres indígenas experimentan cotidianamente distintas formas de discriminación y exclusión, así menos de la mitad $(40,9 \%)$ de las comunidades indígenas cuenta con botiquines, contribuyendo a mantener la alta prevalencia de mortalidad materna (de 3516 muertes registradas, 98 tienen como causa un parto complicado). Según el Ministerio de Salud (2007) 'ser indígena aumenta las probabilidades de ser pobre de $13 \%$ a $30 \%$. Los indicadores de salud son peores entre los indígenas (mortalidad materna, mortalidad infantil, desnutrición, cobertura del parto hospitalario, vacunas, etc.). La mitad de muertes ocurren antes de los 42 años, veinte menos de vida en relación al promedio nacional"18.
\end{abstract}

No hay datos estadísticos precisos sobre el porcentaje de la población que sufre de algún tipo de discriminación racial o étnica debido a la falta de preguntas sobre el tema, que ayuden a tipificar este problema, en las encuestas realizadas a la población. Sobre la naturalización de la discriminación racial, de género o de orientación sexual, Ardito (s/f) mencionaba que: "la intervención del Estado peruano ha sido muy débil. No se ha llevado a cabo ninguna campaña contra el racismo en los medios de comunicación o en el currículo escolar. Antes bien, se tiende a reproducir estereotipos y/o a no representar la composición multirracial de nuestro país".

La situación de discriminación de la mujer peruana está muy ligada a su situación racial, étnica, socioeconómica y educativa. Sin embargo, por lo general el problema de violencia sexual y de género, entre otras maneras de discriminación, es algo que está muy vigente en todos los estratos socioeconómicos, grupos raciales y niveles educativos en la sociedad peruana. Otro problema es el poco conocimiento y acceso a los derechos de salud y reproductivos por parte de las mujeres peruanas. Existe todavía una tasa alta de mortalidad materna y embarazos adolescentes, así como una amplia práctica de abortos ilegales, siendo que uno de los problemas más serios es el acceso a los servicios de salud.

"Según la ENDES (2013) el 94,5\% de las mujeres reportaron algún "problema para acceder a servicios. Entre 
las razones, señalaron: La necesidad de 'tener que tomar transporte' para acceder a los servicios de salud, vinculada con el dinero y distancia, siendo un grave problema en Apurímac (69,9\%), Amazonas (66,5\%), Puno $(62,5 \%)$ y Cajamarca $(61,6 \%)$; el $82,4 \%$ de mujeres afirmaron que 'no habría personal calificado que la atienda' y el 56,5\% de mujeres mencionó que 'no habría personal femenino' que atienda en la consulta (cifras a nivel nacional), dichos porcentajes se agudizan en las zonas de selva y sierra" ${ }^{\prime \prime}$.

Si bien existen iniciativas para la erradicación de la discriminación contra la mujer, como las leyes de la Prevención y Sanción del Hostigamiento Sexual o el Plan Nacional de Igualdad de Oportunidades para el Hombre y la Mujer, ambas del año 2003, sin embargo, en la práctica estas leyes no cumplen su función, debido al alto nivel de acoso sexual cotidiano que aún existe hacia las mujeres peruanas y a la vigencia de un machismo y patriarcalismo en la cultura peruana, los cuales se expresan a través de los medios de comunicación, de los medios de entretenimiento y en las relaciones personales.

\footnotetext{
"La violencia contra las mujeres tiene tasas muy altas entre la población rural. Según la Encuesta Demográfica y de Salud Familiar (ENDES, 2013), el 74\% de las mujeres alguna vez unidas sufrió algún tipo de violencia por parte de su esposo o compañero. Del total, el 69.3\% reportó violencia psicológica, el 38\% violencia física y $8.5 \%$ violencia sexual” 20 .
}

Otros tipos de discriminación que se manifiestan en la sociedad peruana son contra las personas homosexuales, bisexuales o transexuales, contra los portadores del VIH o del SIDA y contra las personas con necesidades especiales. La discriminación contra los portadores deVIH o SIDA se debe a la poca educación sobre las maneras de transmisión de esta enfermedad, ya que un gran sector de la población aún piensa que el virus se puede transmitir meramente por contacto o cercanía física.

\footnotetext{
"Si bien la tasa de contagio en el Perú se ha reducido respecto del año pasado (en el 2006 el Ministerio de Salud registró 4 mil 89 casos deVIH y SIDA, mientras que este año se han registrado 2 mil 7 casos), aún la presencia de este virus - que sólo se transmite por transfusión de sangre, madre a hijo o por el contacto sexual - causa un profundo rechazo en un sector de la población y
}

sobre todo en el imaginario popular que viaja de persona en persona" 21 .

Una forma de discriminación contra la comunidad LGBT es la violencia contra ellos, que no ha producido efectos concretos que se traduzcan en políticas públicas de lucha contra la intolerancia. La falta de atención también alcanza a las personas con necesidades especiales, situación que no facilita su incorporación y reconocimiento social en el caso de servicios públicos como transporte y educación, además de una serie de prejuicios culturales que nunca fueron colocados en la agenda pública peruana.

Así, la distribución y objetivación de los derechos económicos, sociales y culturales de un segmento importante de la sociedad peruana son recibidos de forma asimétrica, dada la baja efectividad y calidad de la implementación de las políticas públicas en los distintos niveles y subniveles de la esfera pública.

\section{A manera de conclusión}

Entre las ocho dimensiones de la calidad democrática en el Perú, la de mayor puntuación, libertad (con 4,0 en la escala de 5,0 puntos), nos señala que sin una amplia libertad de expresión y de asociación no puede haber democracia. Es verdad que se respeta la libertad de organización, pero con algunas excepciones como es el caso de excluir organizaciones políticas antisistema. Sin embargo el principal problema está asociado a las limitaciones de los derechos civiles, la discriminación y la intolerancia.

La rendición de cuentas electoral (con 3,9 puntos) es la forma principal por la que los ciudadanos pueden controlar a sus gobernantes. En el Perú las elecciones a nivel nacional y regional resultan en cambios frecuentes de líderes y de las organizaciones políticas en el poder cuando éstos no satisfacen las expectativas de los ciudadanos, y en esta medida se está realizando la rendición de cuentas electoral. Sin embargo esta rendición es más débil en la falta de alternativas estables por cuenta de una alta volatilidad electoral, lo que implica una baja institucionalización de los partidos políticos.

Otra forma de controlar a los gobernantes es la rendición de cuentas interinstitucional (con 3,6 puntos en el Perú), que se refiere principalmente a la capacidad que tienen las distintas instituciones del Estado para vigilar, exigir información y sancionar a los actores claves de las otras instituciones del Estado si éstos exceden

19 Informe alterno al Comité para la Eliminación de la Discriminación Racial (CERD) de las Naciones Unidas - Perú, 2013, p. 5

20 Informe alterno al Comité para la Eliminación de la Discriminación Racial (CERD) de las Naciones Unidas - Perú, 2013, p. 6

21 POMAREDA, Alfredo, "VIH aún es sinónimo de discriminación", La República, 19 de noviembre de 2007, disponible en <http://larepublica. pe/19-11-2007/vih-aun-es-sinonimo-de-discriminacion> 
sus funciones delimitadas por la Constitución o las leyes. A veces se llama accountability horizontal a este tipo de rendición de cuentas por tratarse de relaciones de control dentro del Estado, a diferencia del control ejercido por los ciudadanos desde fuera del Estado por medios electorales.

Ya la competencia política (con 3,6 puntos) es necesaria para la rendición de cuentas electoral y para muchos es vista como la dimensión más importante para la democracia moderna. En este rubro también consideramos la competencia que se da dentro de cada organización política y social, ya que es muchas veces de una calidad muy distinta a la calidad de la competencia entre organizaciones. En el Perú la competencia entre partidos suele ser mucho más fuerte que dentro de las organizaciones políticas, centrando la competencia electoral en la figura del candidato, y no en las instituciones partidarias.

La participación política ( 3,3 puntos) es otra dimensión fundamental para la existencia de la democracia moderna, ya que la exclusión del derecho a sufragar ha sido históricamente uno de los más importantes límites de la democracia. Desde que se reconoció el derecho de los analfabetos a sufragar en la Constitución de 1979, el sufragio en el Perú ha sido no solo universal sino también obligatorio. La participación en las organizaciones políticas es baja, y la participación en protestas lleva con cierta frecuencia a actos de represión violenta por parte de las autoridades y a actos violentos de quienes protestan, lo que pesa negativamente sobre la calidad de la participación. Un ejemplo de ello es que durante el gobierno de García murieron 191 personas en el contexto de conflictos sociales. Una mayor rigidez viene continuando con el actual gobierno de Humala, quien aprobó la Ley 30.151 que exime de toda responsabilidad penal a los policías y militares que causen lesiones o la muerte a terceros en acción de servicio. En esa perspectiva y en un contexto de resolución de conflictos sociales la situación se torna cada vez más peligrosa.

El imperio de la ley (3,0 puntos) es quizás la dimensión más compleja de las ocho, y aunque su presencia no implica que las otras dimensiones sean de- pendientes. La ausencia del imperio de la ley tiende a socavar las otras dimensiones y deslegitimarlas. A lo largo de su historia el imperio de la ley ha brillado por su ausencia en buena parte del territorio peruano. Si en la actualidad el Perú muestra un significativo control civil de las fuerzas de seguridad, las debilidades más importantes son en la lucha contra la corrupción, la seguridad individual, el funcionamiento del sistema judicial y la capacidad institucional del mismo para ejecutar la ley. La percepción sobre esta cuestión puede verificarse en que el $67 \%$ de los peruanos no cree que se cumplen las leyes en el país.

Una de las dimensiones más débiles de la calidad de la democracia en el Perú es la de responsabilidad y legitimidad (2,8 puntos). La democracia representativa es una forma de gobierno por el pueblo en cuanto los ciudadanos dirigen y controlan a sus gobernantes y éstos responden a los ciudadanos. Esta dimensión se traduce en la capacidad de los gobernantes para responder a las necesidades y a las aspiraciones de los ciudadanos y está estrechamente vinculada a la legitimidad, confianza, y satisfacción con la que los ciudadanos perciben a quienes gobiernan. En el Perú se observan niveles muy bajos de confianza en las instituciones, y hay poca satisfacción con el funcionamiento de la democracia. Al mismo tiempo se ha visto una tendencia a mejorar en este sentido, lo cual abre esperanzas hacia el futuro en perfeccionar los mecanismos de intermediación entre gobierno y ciudadanía, que bien podrían contribuir a disminuir las tensiones sociales.

En la dimensión de igualdad y solidaridad (2,3 puntos) el desempeño de la democracia peruana está peor, aunque se han visto cambios importantes. La pobreza y la desigualdad son características profundamente enraizadas en el Perú, marcando las relaciones sociales y políticas de diversas maneras. Hay una distribución de los recursos muy desigual, altos niveles de pobreza, persistencia de discriminaciones de todo tipo e insatisfacción de derechos sociales básicos. Si bien se ha visto una tendencia a reducir la pobreza y la desigualdad, aún queda mucho por combatir de las discriminaciones y que se incremente cada vez más el porcentaje de quienes tienen satisfechos sus derechos sociales básicos.

\section{Referencias}

ALCÁNTARA SÁEZ, Manuel. Partidos políticos en América Latina: hacia una profesionalización de calidad. Convergencia, v. 19, n. 58, p. 53-70, 2012.

ARDITO, Wilfredo. Racismo en el Perú y estándares internacionales. Instituto de Defensa Legal, s/f. Disponible en <http://www.idl.org.pe/idlrev/revistas/117/pag15.htm>. ARGUEDAS, José María. Cultura y Pueblo, v. 5, n. 15-16, p. 3, 1969
BUNKER, Kenneth; NAVIA, Patricio. Explicando la desproporcionalidad en América Latina: magnitud de distrito, malapportionment y fragmentación partidaria. Revista Española de Ciencia Política, n. 23, p. 81-110, 2010.

CARRIÓN, Julio F; ZÁRATE, Patricia; SELIGSON, Mitchell A. Cultura política de la democracia en Perú, 2010. Consolidación democrática en las Américas en tiempos difíciles. Lima y Nashville, TN: Instituto de Estudios Peruanos y 
Vanderbilt University, 2012.

DAHL, Robert. La democracia y sus críticos. Buenos Aires: Paidós. 1989.

FELD, Lars P.; VOIGT, Stefan. Economic growth and judicial independence: cross-country evidence using a new set of indicators. European Journal of Political Economy, v. 19, n. 3 , p. 497-527, 2003.

GALLAGHER, Michael. Proportionality, disproportionality, and electoral systems. Electoral Studies, v. 10, n. 1, p. 33-51, 1991.

LIJPHART, Arend. Electoral systems and party systems: a study of twenty-seven democracies, 1945-1990. Nueva York: Oxford University Press, 1994.

LOOSEMORE, John; HANBY, Vincent. The theoretical limits of maximum distortion: some analytic expressions for electoral systems. British Journal of Political Science, v. 1, p. 467-477, 1971.

MAINWARING, Scott; SCULLY, Timothy R. Party systems in Latin America. En: MAINWARING, Scotty; SCULLY, Timothy R. (eds.). Building democratic institutions: party systems in Latin America. Stanford, CA: Stanford University Press, 1995.

MAINWARING, Scott; BEJARANO, Ana María; PIZARRO, Eduardo (eds.). La crisis de la representación democrática en los países andinos. Bogotá: Norma, 2008.

MORLINO, Leonardo. Changes for democracy. Oxford: Oxford University Press, 2011.

Programa de las Naciones Unidas para el Desarrollo (PNUD). La democracia en América Latina: hacia una democracia de ciudadanas y ciudadanos. Buenos Aires: Aguilar, Altea, Taurus, Alfaguara, 2004.

REYNOSO, Diego. Las consecuencias políticas de la sobre-representación distrital. Política y Gobierno, v. 9, n. 2, p. 325-359, 2002.

REMY, María Isabel. ¿Son representativos los gobiernos regionales? Revista Argumentos, v. 4, n. 1, 2010.

SAMUELS, David. Concurrent elections, discordant results: presidentialism, federalism, and governance in Brazil. Comparative Politics, v. 33, n. 1, p. 1-20. 2000.

SÁNCHEZ, Omar. Party non-systems. Party Politics, v. 15, n. 4, p. 487-520, 2009.

SANTANDER, Carlos Ugo. Democracia y elecciones en el Perú: tendencias, desafios y perspectivas. In: SANTANDER, Carlos Ugo (comp.) Los desafíos de la democracia y elecciones en América Latina. Lima: ARAE, 2008.

TAAGEPERA, Rein; SHUGART, Matthew S. Seats and votes. The effects and determinants of electoral systems. New Haven y Londres:Yale University Press, 1989.

\title{
The quality of democracy in Peru
}

\begin{abstract}
:
This paper analyzes the Peruvian democratic experience from a theoretical and methodological framework presented by Leonardo Morlino on the quality of democracy. In summary, it seeks to go from transitology studies - typical from the 1980s and 1990s, when countries such as Peru and its neighbors manage their democratic transition and consolidation - towards research studies which the primary concern is the quality of democracy. Despite the authoritarian regression in the 1990s and the return to democratic regime in 2001, Peruvian democracy still has a number of challenges that can lead to a new authoritarian regression or to the devaluation of democracy. There is clear evidence with significant results regarding political rights and the monitoring of governments and institutions, but the problems are concentrated in the dimensions related to accountability and legitimacy, rule of law, and solidarity and equality.
\end{abstract}

Key words: Peru; quality of democracy; accountability and legitimacy; authoritarian rule; solidarity and equality.

\section{A qualidade da democracia no Peru}

\section{Resumo:}

Este trabalho analisa a experiência democrática peruana a partir do referencial teórico-metodológico apresentado por Leonardo Morlino sobre qualidade da democracia. Resumidamente, se trata de passar dos estudos de transitologia - próprios das décadas de 1980 e 1990 , quando países como o Peru e seus vizinhos alcançaram suas respectivas transições e consolidações democráticas - em direção a investigações preocupadas com a qualidade da democracia. Apesar da regressão autoritária nos 1990 e da volta ao regime democrático em 2001, a democracia peruana ainda apresenta uma série de desafios que podem levar à outra regressão autoritária ou à própria desvalorização da democracia. Existem claras evidencias com resultados significativos em dimensões relacionadas aos direitos políticos e ao controle de governantes e instituições, mas os problemas se concentram nas dimensões relacionadas a responsabilidade e legitimidade, Estado de Direito e igualdade e solidariedade.

Palavras-chave: Peru; qualidade da democracia; responsabilidade e legitimidade; autoritarismo; solidariedade e igualdade. 
